\title{
Nationwide population-based study reveals increased malignancy risk in taiwanese liver transplant recipients
}

\author{
Yung Fong Tsai ${ }^{1,2}$, Hsiu Pin Chen ${ }^{1,2}$, Fu Chao Liu ${ }^{1,2}$, Shih Hao Liư ${ }^{3}$, Chun Yu Chen ${ }^{1,2}$, \\ Chih Wen Cheng ${ }^{1}$ and Jr Rung Lin ${ }^{1,2,3}$ \\ ${ }^{1}$ Department of Anesthesiology, Chang Gung Memorial Hospital, Taoyuan, Taiwan \\ ${ }^{2}$ College of Medicine, Chang Gung University, Taoyuan, Taiwan \\ ${ }^{3}$ Clinical Informatics and Medical Statistics Research Center and Graduate Institute of Clinical Medicine, Chang Gung \\ University, Taoyuan, Taiwan \\ Correspondence to: Jr Rung Lin, email: jr@mail.cgu.edu.tw \\ Keywords: de novo malignancy; immunosuppression; mortality; post-transplant malignancy; recurrent malignancy \\ Received: April 08, $2016 \quad$ Accepted: September 02, $2016 \quad$ Published: September 10, 2016
}

\section{ABSTRACT}

Post-transplant malignancy is a major cause of late mortality for liver transplant recipients (LTRs). This nationwide population-based cohort study investigated the cancer type, incidence, and risk factors associated with post-transplant malignancies in 2938 Taiwanese LTRs who underwent transplantation between 1998 and 2012. Data from the National Health Insurance Research Database were extracted on the basis of the International Classification of Disease, Ninth Revision, Clinical Modification codes. Among these patients, 284 post-transplant malignancies were diagnosed. These included 99 de novo malignancies among 98 patients, yielding a standardized incidence ratio of 2.17 ( $95 \%$ CI, 1.76 to 2.64 ) compared to the general population. The most common malignancies were infection related liver cancer (19.39\%), oropharyngeal cancer (19.39\%), non-Hodgkin's Iymphoma (9.18\%), and esophageal cancer (5.10\%), as well as non-infection-related prostate cancer (6.12\%). Patients with recurrent malignancies had the highest mortality. Furthermore, 186 recurrent malignancies relapsed, and the commonly affected organs were the liver (83.33\%), lung (4.84\%), bone and bone marrow (4.30\%), and intrahepatic bile ducts (2.69\%). Old age, the male sex, liver cirrhosis, hepatitis B, peptic ulcer, diabetes mellitus, and pre-existing cancer were all risk factors associated with post-transplant malignancies. Recipients with biliary atresia or urea cycle metabolism disorders were protected from post-transplant malignancies. Our data revealed a significantly increased risk of malignancies in Taiwanese LTRs and suggest implementation of a careful malignancysurveillance program and immunosuppression-minimizing strategy for high-risk patients.

\section{INTRODUCTION}

Liver transplantation is an effective and promising choice to cure patients with end-stage liver diseases or early inoperable hepatocellular carcinoma (HCC) [1], who otherwise have less than one year to live [2]. Advances in surgical techniques and medical care have lately yielded a one-year survival rate after liver transplantation of more than $80 \%-90 \%[3,4]$. However, liver transplant recipients (LTRs) still have a lower probability of long-term survival than the age-matched general population [5]. Closely followed by common causes of death in the general population, hepatic-related, post-transplant malignancies account for $22 \%$ of LTR mortality [6]. Several epidemiological studies have revealed a 2- to 4-fold higher risk of post-transplant de novo malignancies in LTRs than in the general population [5, 7-9]. Immunosuppression is an essential contributor to oncogenesis in LTRs, particularly for those with infection-related cancers. This viewpoint was firmly supported by the similar spectrum of cancer risk seen in LTRs and patients with acquired immunodeficiency syndrome (AIDS) [10]. 
Malignancies occurring after solid organ transplantations, other than liver, are mainly de novo cancers because recipients with active malignancies are typically excluded. Recipients with HCC typically have poor survival and considerably elevated recurrence rates because of poor patient selection [13, 14]. The Milan criteria have been widely used for candidate selection since 1996, and five-year survival obtained using these criteria was more satisfactory than that obtained using others $(87 \%$ vs. 62\%) [15]. In Taiwan, the first liver transplantation for HCC was performed in 1999. Because transplantation for $\mathrm{HCC}$ has since become well accepted in Taiwan, recurrent malignancies among LTRs could become an increasingly serious problem.

Few studies have summarized and compared de novo and recurrent malignancies after liver transplantation. Of these, many were limited by a single-center design or small cohort population and they rarely analyzed risk factors associated with post-transplant malignancies in LTRs $[9,11,12,16]$. Determining risk factors for posttransplant malignancies provides a basis for preventive and therapeutic interventions and could promote early diagnosis and improve long-term survival. The present study aimed to retrospectively determine the patterns of post-transplant malignancies and associated risk factors. The spectrum and prevalence of post-transplant malignancies vary among ethnicities and geographical regions. We herein analyzed the incidence of de novo and recurrent malignancies in Taiwanese LTRs over a 14.5-year observation period compared to the general population. As per our review of relevant data, our study is the first to provide insights into cancer etiology and support the development of evidence-based strategies for identifying high-risk recipients by examining patients of Chinese ethnicity.

\section{MATERIALS AND METHODS}

\section{Data source}

This population-based cohort study retrospectively analyzed data from Taiwan's National Health Insurance Research database (NHIRD). It enrolled more than $99.9 \%$ of the entire population of 23.32 million Taiwanese residents, and the Bureau of National Health Insurance (NHI) is affiliated to more than $93 \%$ medical institutions in Taiwan. The claims data retrieved from the NHIRD were computerized and de-identified. The NHIRD comprises enrollment information, inpatient and outpatient claims for reimbursement, and prescription drugs and procedures. Furthermore, the database provides disease diagnostic codes according to the International Classification of Disease, Ninth Revision, Clinical Modification (ICD-9$\mathrm{CM})$. In addition, the annual incidence rate of cancer in the general population was obtained from the Taiwan National Cancer Registry (http://www.hpa.gov.tw/BHPNet/Web / Stat/StatisticsShow.aspx?No = 200911300001, and http:// www.hpa.gov.tw/BHPNet/ Web/ Stat/Statistics.aspx).

The study protocol conformed to the ethical guidelines of the 1975 Declaration of Helsinki as reflected in a priori approval by the Institutional Review Board of Chang Gung Memorial Hospital (Registration number: IRB 103-0102B) and NHIRD research committee (Registration number: NHIRD-103-103). Personal information and medical records were identified and anonymized; therefore, informed consent from the LTRs was unavailable.

\section{Definition and selection of the study population}

The target LTRs were identified on the basis of the ICD-9-CM code 996.82 or V427 from the catastrophic illness database. In addition, we excluded patients who did not match the operation code of liver transplant surgery $(505,75020 \mathrm{~A}$, or $75020 \mathrm{~B})$ within this period. Finally, 2938 LTRs were included in this cohort study.

Preoperative comorbidities were identified using a preset definition of at least one recorded inpatient department diagnosis or five recorded outpatient department diagnoses before transplantation using the claimed codes. The specific ICD-9-CM codes for identification are as follows: liver cirrhosis (ICD-9-CM 571.2, 571.5, and 571.6), chronic hepatitis (ICD-9-CM 070, 571, and 573.3), alcoholic hepatitis (ICD-9-CM 571.2 and 571.3), hepatitis B (ICD-9-CM 070.2, 070.3, V0261, and V0269), hepatitis C (ICD-9-CM 070.41, 070.44, 070.51, 070.54, 070.7, and V262), hypertension (ICD-9CM 401-405), diabetes mellitus (ICD-9-CM 250), peptic ulcer (ICD-9-CM 531-533), obesity (ICD-9-CM 278), ascites (ICD-9-CM 789.5), hepatic coma (ICD-9-CM 070.0, 070.2, 070.4, 070.6, 70.2, 70.41, 572.2, 070.71, and 348.3), renal failure (ICD-9-CM 584-586), pulmonary disease (ICD-9-CM 490-496), hypercholesterolemia (ICD-9-CM 272), malignancies (ICD-9-CM 140-208.91), biliary atresia (ICD-9-CM 751.61), Wilson disease (ICD9-CM 275.1 and E8301), glycogen storage disease (ICD9-CM 271.0), urea cycle metabolism disorders (ICD-9CM 270.6), bacteremia (ICD-9-CM 038 and 998.5), and postoperative bleeding (ICD-9-CM 998.0-998.2). Death was defined as the matched death code or termination from the NHI program.

\section{Definition of primary outcome}

The primary outcomes were post-transplant malignancies and long-term mortality in the LTRs. Post-transplant cancers were defined according to the recorded ICD-9-CM codes 140-208.91 in the same catastrophic illness database after liver transplantation. 
Benign neoplasms (ICD-9-CM 210-229) and in situ carcinoma (ICD-9-CM 230-234) were not included as post-transplant malignancies. To avoid bias in the posttransplant malignancy rate, which may be caused by an increased pre-transplantation examination, patients diagnosed with cancer within 3 months postoperatively were excluded. Furthermore, de novo cancer is defined as the first occurrence without a prior existence of that cancer in the body. Recurrent malignancy is defined as cancer reappearance after a remission interval when the cancer cannot be detected. The relapsed cancer can develop at the original location or in other parts of the body. Variables comprised demographic characteristics, and comorbidities were analyzed for the risk factors for post-transplant malignancies.

The survival time of the LTRs was defined as the number of days from transplantation to death. For comparison of long-term survival LTRs were categorized into four groups: 1. Malignancy-free group, no cancer diagnosed throughout the study period; 2. Malignancycured group, preoperative malignancies were not diagnosed postoperatively. 3. De novo group, the first occurrence of cancer postoperatively; and 4. Recurrent group, the postoperative development of relapsed cancer, which existed preoperatively.

\section{Statistical analysis}

Data are expressed as means \pm standard deviation, except the representatives of the survival time that are presented as mean \pm standard error (SE). Statistical analysis was performed using SAS (version 9.3; SAS Institute Inc., Cary, NC, USA). The variables for comparing the risk factors between the malignancy and non-malignancy groups were expressed as competing risk cox regression model with control mortality. Patient death or loss to follow-up in the NHIRD was identified as patient mortality. A $p$-value of $<0.05$ was considered significant, and all statistical analyses were two-sided.

\section{RESULTS}

\section{Characteristics of the LTRs}

We recruited 2938 Taiwanese LTRs who underwent transplantation between July 1998 and December 2012; patient characteristics are described in Table 1. Of all LTRs, 2068 were males, and 870 were females; 341 were pediatric patients less than 18 years old. The average age at the time of the transplant was $46.42 \pm 17.68$ years (range, 4.44 months to 75.15 years; median, 51.76

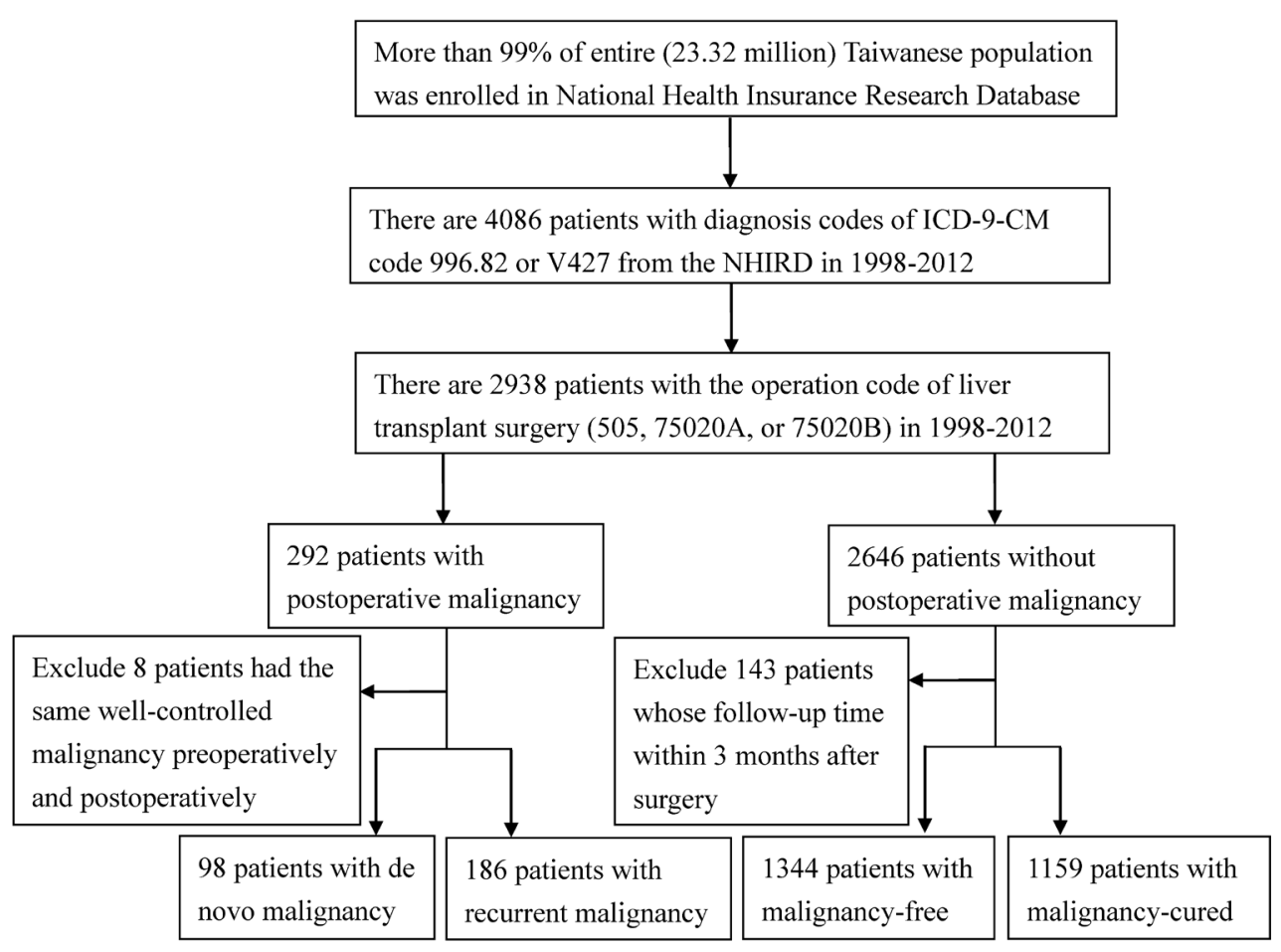

Figure 1: Flowchart. ICD-9-CM, International Classification of Disease, Ninth Revision, Clinical Modification; NHIRD, National Health Insurance Research Database. 
Table 1: Characteristics of Taiwan liver transplant recipients from 1998 through 2012.

\begin{tabular}{|c|c|c|}
\hline $\mathbf{N}=\mathbf{2 9 3 8}$ & N, Mean & $\%$, SD \\
\hline \multicolumn{3}{|l|}{$\overline{\operatorname{Sex}}$} \\
\hline Male & 2068 & 70.39 \\
\hline Female & 870 & 29.61 \\
\hline$\overline{\text { Age }(\text { years) })^{\dagger}}$ & 46 & 17.68 \\
\hline \multicolumn{3}{|l|}{ Age group } \\
\hline$<18$ & 341 & 11.61 \\
\hline$\geqq 18$ & 2597 & 88.39 \\
\hline Follow-up time (years) ${ }^{\dagger}$ & 3.79 & 3.26 \\
\hline$<1$ & 623 & 21.20 \\
\hline $1-5$ & 1466 & 49.90 \\
\hline $5-10$ & 667 & 22.70 \\
\hline$>10$ & 182 & 6.19 \\
\hline Person-years of follow-up & 14176 & \\
\hline \multicolumn{3}{|l|}{ Pre-op cancer } \\
\hline Yes & 1440 & 49.01 \\
\hline No & 1498 & 50.99 \\
\hline \multicolumn{3}{|l|}{ Pre-op HCC } \\
\hline Yes & 1313 & 44.69 \\
\hline No & 1625 & 55.31 \\
\hline Liver cirrhosis & 2484 & 84.55 \\
\hline \multicolumn{3}{|l|}{ Chronic hepatitis } \\
\hline Yes & 2761 & 93.98 \\
\hline HBV-related & 1416 & 48.20 \\
\hline HCV-related & 662 & 22.53 \\
\hline Alcohol-related & 565 & 19.23 \\
\hline No & 177 & 6.02 \\
\hline \multicolumn{3}{|l|}{ Biliary atresia } \\
\hline Yes & 284 & 9.67 \\
\hline No & 2654 & 90.33 \\
\hline \multicolumn{3}{|l|}{ Wilson's disease } \\
\hline Yes & 35 & 1.19 \\
\hline No & 2903 & 98.81 \\
\hline \multicolumn{3}{|l|}{ Glycogen storage disease } \\
\hline Yes & 28 & 0.95 \\
\hline No & 2910 & 99.05 \\
\hline \multicolumn{3}{|c|}{ Urea cycle metabolism disorders } \\
\hline Yes & 16 & 0.54 \\
\hline No & 2922 & 99.46 \\
\hline
\end{tabular}

${ }^{\dagger}$ Values are mean and standard deviation. HCC, hepatocellular carcinoma.

years). The average follow-up interval was $3.79 \pm 3.26$ years, with a total follow-up of 14176 person-years. The most common follow-up duration was between 1 and 5 years, and $6.19 \%$ of the LTRs were followed for more than 10 years. Furthermore, 1440 LTRs were diagnosed with preoperative malignancies, 1313 of these with liver cancer $(91.18 \%)$. The other 1498 LTRs were cancer-free preoperatively. 2484 patients had liver cirrhosis. Among the 2761 cases of chronic hepatitis, 1416 were HBV related, 662 were $\mathrm{HCV}$ related, and 565 were alcohol related.
Risk of post-transplant malignancies in the LTRs
compared with the general Taiwanese population

The annual incidences of malignancies for the estimated Taiwanese population of 23.32 million as of 2012 are listed in Table 2. The average annual incidence of de novo malignancies from 1998 to 2012 was approximately $0.32 \%$ in the general population. In the LTRs, the proportion of total post-transplant malignancies was $9.67 \%$, the proportion of de novo malignancies was 
Table 2: Annual number of patients with de novo malignancy in cohort study and general Taiwan population from 1998 through 2012.

\begin{tabular}{|c|c|c|c|c|c|c|}
\hline \multirow[b]{2}{*}{ Year } & \multicolumn{2}{|c|}{ General population } & \multicolumn{4}{|c|}{ Cohort population } \\
\hline & $\begin{array}{l}\text { De novo } \\
\text { malignancy }\end{array}$ & $\begin{array}{l}\text { Population } \\
\text { number }\end{array}$ & $\begin{array}{l}\text { De novo } \\
\text { malignancy }\end{array}$ & $\begin{array}{l}\text { Recurrent } \\
\text { malignancy }\end{array}$ & $\begin{array}{c}\text { Transplant } \\
\text { recipient }\end{array}$ & $\begin{array}{c}\text { Cumulative } \\
\text { person-years of follow-up }\end{array}$ \\
\hline 1998 & 52207 & 21928591 & 0 & 0 & 12 & 180 \\
\hline 1999 & 56323 & 22092387 & 0 & 0 & 29 & 586 \\
\hline 2000 & 59116 & 22276672 & 0 & 0 & 40 & 1106 \\
\hline 2001 & 61606 & 22405568 & 0 & 0 & 64 & 1874 \\
\hline 2002 & 63736 & 22520776 & 0 & 3 & 70 & 2644 \\
\hline 2003 & 62542 & 22604550 & 4 & 2 & 134 & 3984 \\
\hline 2004 & 67895 & 22689122 & 9 & 8 & 108 & 4956 \\
\hline 2005 & 68907 & 22770383 & 3 & 7 & 158 & 6220 \\
\hline 2006 & 73293 & 22876527 & 8 & 7 & 179 & 7473 \\
\hline 2007 & 75769 & 22958360 & 5 & 16 & 227 & 8835 \\
\hline 2008 & 79818 & 23037031 & 8 & 12 & 289 & 10280 \\
\hline 2009 & 87189 & 23119772 & 13 & 25 & 326 & 11584 \\
\hline 2010 & 90649 & 23162123 & 16 & 41 & 406 & 12802 \\
\hline 2011 & 92682 & 23224912 & 14 & 46 & 478 & 13758 \\
\hline 2012 & 96694 & 23315822 & 18 & 19 & 418 & 14176 \\
\hline Total & 1088425 & & 98 & 186 & 2938 & \\
\hline
\end{tabular}

$3.34 \%(98 / 2938)$, and that of recurrent malignancies was $6.33 \%$ (186/2938). Moreover, the standardized incidence ratio (SIR) of de novo cancer between LTRs and the general population was 2.17 (95\% CI, 1.76 to 2.64$)$.

\section{Incidence and mortality of post-transplant malignancies}

Of the 2938 LTRs, 2795 were followed for more than 3 months postoperatively. 284 LTRs had posttransplant malignancies, including de novo or recurrent

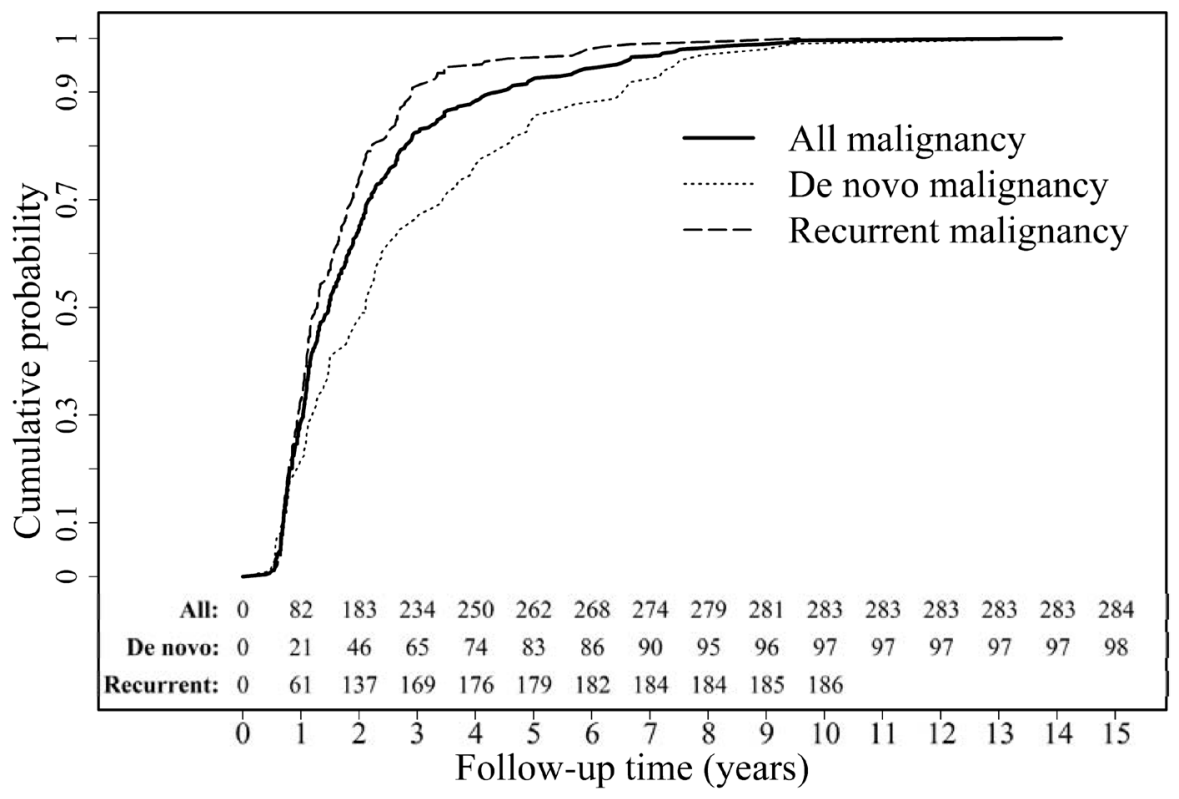

Figure 2: Cumulative cancer probability of de novo, recurrent, and all malignancies in the liver transplant recipients. 
Table 3: Type, incidence, and malignancy-free interval after liver transplantation.

\begin{tabular}{|c|c|c|c|c|}
\hline & \multirow{2}{*}{ Number } & \multicolumn{3}{|c|}{$\begin{array}{c}\text { Malignancy-free interval } \\
\text { (years) }\end{array}$} \\
\hline & & Median & Minimal & Maximal \\
\hline \multicolumn{5}{|l|}{ De novo malignancy $(N=98)$} \\
\hline Oral cavity & 6 & 2.21 & 0.66 & 6.41 \\
\hline Pharynx & 13 & 2.17 & 0.47 & 7.92 \\
\hline Esophagus & 5 & 4.27 & 1.12 & 5.71 \\
\hline Stomach & 3 & 6.59 & 2.25 & 6.66 \\
\hline Small intestine & 1 & 2.11 & 2.11 & 2.11 \\
\hline Colon & 2 & 1.54 & 1.26 & 1.83 \\
\hline Rectum & 2 & 2.21 & 1.47 & 2.95 \\
\hline Liver & 19 & 1.49 & 0.55 & 5.45 \\
\hline Ampulla of Vater & 1 & 0.89 & 0.89 & 0.89 \\
\hline Gallbladder and extrahepatic bile ducts & 1 & 4.96 & 4.96 & 4.96 \\
\hline Pancreas & 1 & 3.95 & 3.95 & 3.95 \\
\hline $\begin{array}{l}\text { Ill-defined sites within the digestive organs and } \\
\text { peritoneum }\end{array}$ & 1 & 14.08 & 14.08 & 14.08 \\
\hline Larynx & 2 & 4.95 & 2.39 & 7.52 \\
\hline Lung & 4 & 1.13 & 0.56 & 8.99 \\
\hline Pleura & 1 & 1.89 & 1.89 & 1.89 \\
\hline Connective tissue & 1 & 1.05 & 1.05 & 1.05 \\
\hline Skin & 1 & 7.17 & 7.17 & 7.17 \\
\hline Breast & 4 & 1.55 & 0.56 & 2.53 \\
\hline Kaposi's sarcoma & 2 & 0.89 & 0.66 & 1.12 \\
\hline Cervix uteri & 2 & 2.74 & 1.39 & 4.08 \\
\hline Prostate & 6 & 3.09 & 0.85 & 9.47 \\
\hline Bladder & 2 & 4.78 & 3.04 & 6.52 \\
\hline Kidney & 1 & 0.57 & 0.57 & 0.57 \\
\hline Brain & 3 & 1.27 & 0.99 & 4.89 \\
\hline Thyroid gland & 1 & 7.44 & 7.44 & 7.44 \\
\hline Non-Hodgkin's lymphoma & 9 & 2.27 & 0.58 & 4.90 \\
\hline Hodgkin's disease & 1 & 3.53 & 3.53 & 3.53 \\
\hline Lymphoid leukemia & 2 & 2.74 & 2.04 & 3.45 \\
\hline Myeloid leukemia & 2 & 1.36 & 0.79 & 1.93 \\
\hline Total & 99 & 2.11 & 0.47 & 14.08 \\
\hline \multicolumn{5}{|l|}{ Recurrent malignancy $(N=186)$} \\
\hline Liver & 155 & 1.29 & 0.56 & 9.58 \\
\hline Intrahepatic bile ducts & 5 & 2.15 & 1.65 & 2.71 \\
\hline lymph nodes & 3 & 1.10 & 0.39 & 1.64 \\
\hline Lung & 9 & 0.95 & 0.62 & 8.33 \\
\hline Pleura & 1 & 2.47 & 2.47 & 2.47 \\
\hline Peritoneum & 1 & 0.85 & 0.85 & 0.85 \\
\hline Other digestive organs and spleen & 1 & 1.08 & 1.08 & 1.08 \\
\hline Brain and spinal cord & 2 & 1.11 & 0.98 & 1.24 \\
\hline Bone and bone marrow & 8 & 1.07 & 0.55 & 3.34 \\
\hline Other specified sites & 1 & 1.99 & 1.99 & 1.99 \\
\hline Total & 186 & 1.28 & 0.39 & 9.58 \\
\hline
\end{tabular}


malignancies, while 2503 LTRs followed for more than 3 months postoperatively, were malignancy free throughout the study period. Eight other patients had the same well-controlled malignancies pre- and postoperatively (Figure 1). The 284 LTRs that developed post-transplant malignancies, included 99 de novo cancers among 98 recipients and recurrent cancers in 186 recipients. The characteristics of all postoperative malignancies are summarized in Table 3. In de novo malignancies, the commonly affected organs or disease were the liver $(19.39 \%)$, the oropharynx $(19.39 \% ; 6.12 \%$ of the oral cavity and $13.26 \%$ of the pharynx), non-Hodgkin's lymphoma $(9.18 \%)$, the prostate $(6.12 \%)$, and the esophagus (5.10\%). Moreover, in recurrent malignancies, the commonly invaded organs were the liver $(83.33 \%)$, lung $(4.84 \%)$, bone and bone marrow (4.30\%), and intrahepatic bile ducts $(2.69 \%)$.

The postoperative cumulative cancer probability examined using the Kaplan-Meier curve is presented in Figure 2. The cumulative cancer probability for LTRs at $1,3,5$, and 10 postoperative years was $28.87 \%$ (82/284), 82.39\% (234/284), 92.25\% (262/284), and $99.65 \%$ (283/284), respectively. Furthermore, in de novo malignancies, the cumulative cancer probability at
$1,3,5$, and 10 postoperative years was $21.43 \%$ (21/98), $66.33 \%$ (65/98), 84.69\% (83/98), and 98.98\% (97/98), respectively. The mean time for the first diagnosis of postoperative cancer was 2.10 years (range, 0.39-14.28 years; median, 1.50). Recurrent malignancies developed faster than de novo malignancies. The cumulative cancer probability reached $90 \%$ at 2.91 years and 6.59 years in the recurrent and de novo malignancy groups, respectively.

In this study, 88 patients with postoperative malignancies died, and their mean survival time from diagnosis was $6.07 \pm 0.17$ (mean $\pm \mathrm{SE}$ ) years. For all patients in this cohort there were 428 deaths, and the mean survival time from diagnosis was $9.78 \pm 0.09($ mean $\pm \mathrm{SE})$ years. The mortality rates were significantly higher in the LTRs than in the general population in Taiwan (http:// www.ris.gov.tw/zh_TW/346).

\section{Risk factors associated with post-transplant malignancies}

To analyze and compare the effects of specific risk factors, the LTRs were divided into two groups based on whether they had post-transplant malignancies

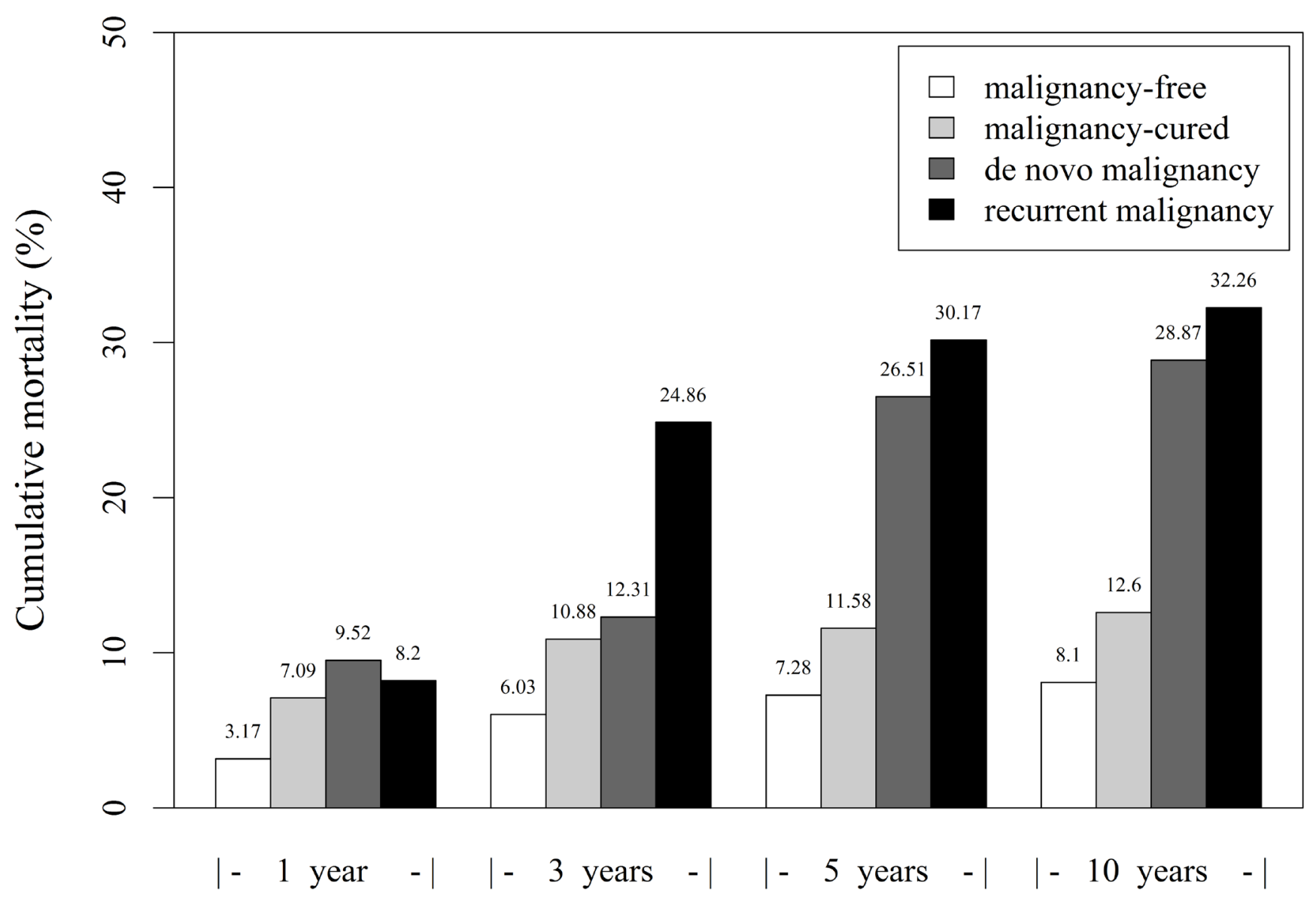

Figure 3: Effects of post-transplant malignancies on the liver transplant recipients by bar plot. 
Table 4: Analysis of risk factors for post-transplant malignancy.

\begin{tabular}{|c|c|c|c|c|c|c|c|}
\hline & \multicolumn{2}{|c|}{$\begin{array}{l}\text { Without malignancy } \\
\text { after transplantation } \\
(N=\mathbf{2 5 0 3})\end{array}$} & \multicolumn{2}{|c|}{$\begin{array}{l}\text { With malignancy } \\
\text { after transplantation } \\
(N=\mathbf{2 8 4})\end{array}$} & \multirow[t]{2}{*}{$\begin{array}{l}\text { Hazard } \\
\text { Ratio }\end{array}$} & \multirow[t]{2}{*}{$(95 \%$ CI $)$} & \multirow[t]{2}{*}{$p$-value } \\
\hline & N or Mean & $\%$ or SD & N or Mean & $\%$ or SD & & & \\
\hline $\mathrm{Age}^{\dagger}$ & 45.90 & \pm 18.10 & 50.29 & \pm 13.36 & 1.03 & $(1.02,1.03)$ & $<.0001$ \\
\hline \multicolumn{8}{|l|}{ Gender } \\
\hline Male & 1742 & 69.60 & 219 & 77.11 & 1.51 & $(1.15,2.00)$ & 0.0033 \\
\hline Female & 761 & 30.40 & 65 & 22.89 & - & - & - \\
\hline \multicolumn{8}{|l|}{ Socioeconomic deprivation } \\
\hline 1(most deprived) & 886 & 35.40 & 87 & 30.63 & 0.70 & $(0.35,1.40)$ & 0.3113 \\
\hline $2(0-2.5 \mathrm{k})$ & 965 & 38.55 & 108 & 38.03 & 0.90 & $(0.45,1.79)$ & 0.7628 \\
\hline $3(2.5 \mathrm{k}-5 \mathrm{k})$ & 481 & 19.22 & 64 & 22.54 & 1.07 & $(0.53,2.18)$ & 0.8447 \\
\hline $4(5 \mathrm{k}-7.5 \mathrm{k})$ & 105 & 4.19 & 16 & 5.63 & 1.14 & $(0.50,2.59)$ & 0.7608 \\
\hline $5(>7.5 \mathrm{k})$ & 66 & 2.64 & 9 & 3.17 & - & - & - \\
\hline Pre-operative cancer & 1159 & 46.30 & 211 & 74.30 & 3.82 & $(2.94,4.96)$ & $<.0001$ \\
\hline Liver cirrhosis & 2105 & 84.10 & 253 & 89.08 & 1.46 & $(1.01,2.13)$ & 0.0468 \\
\hline Ascites & 1196 & 47.78 & 134 & 47.18 & 0.85 & $(0.67,1.07)$ & 0.1684 \\
\hline Chronic hepatitis & 2342 & 93.57 & 274 & 96.48 & 2.00 & $(1.06,3.77)$ & 0.0329 \\
\hline Hepatitis B & 1196 & 47.78 & 156 & 54.93 & 1.37 & $(1.08,1.73)$ & 0.0085 \\
\hline Hepatitis C & 557 & 22.25 & 69 & 24.30 & 1.30 & $(0.99,1.70)$ & 0.062 \\
\hline Alcoholic hepatitis & 482 & 19.26 & 51 & 17.96 & 1.08 & $(0.80,1.46)$ & 0.6235 \\
\hline Hepatic coma & 849 & 33.92 & 93 & 32.75 & 0.92 & $(0.71,1.17)$ & 0.4799 \\
\hline Hypertension & 505 & 20.18 & 53 & 18.66 & 1.14 & $(0.85,1.54)$ & 0.3852 \\
\hline Diabetes mellitus & 512 & 20.46 & 67 & 23.59 & 1.36 & $(1.04,1.79)$ & 0.0264 \\
\hline Peptic ulcer & 1193 & 47.66 & 161 & 56.69 & 1.53 & $(1.21,1.94)$ & 0.0004 \\
\hline Renal failure & 87 & 3.48 & 13 & 4.58 & 1.35 & $(0.78,1.35)$ & 0.2885 \\
\hline Pulmonary disease & 354 & 14.14 & 44 & 15.49 & 1.23 & $(0.89,1.70)$ & 0.2029 \\
\hline Hypercholesterolemia & 331 & 13.22 & 26 & 9.15 & 0.80 & $(0.53,1.20)$ & 0.2731 \\
\hline Biliary atresia & 272 & 10.87 & 12 & 4.23 & 0.28 & $(0.16,0.50)$ & $<.0001$ \\
\hline Wilson's disease & 34 & 1.36 & 1 & 0.35 & 0.20 & $(0.20,1.35)$ & 0.0979 \\
\hline Glycogen storage disease & 26 & 1.04 & 1 & 0.35 & 0.25 & $(0.03,1.84)$ & 0.1734 \\
\hline Urea cycle metabolism disorders & 16 & 0.64 & 0 & 0.00 & 0.00 & $(0.00,0.00)$ & $<.0001$ \\
\hline Obese & 10 & 0.40 & 2 & 0.70 & 1.91 & $(0.50,7.39)$ & 0.3466 \\
\hline Bacteremia & 137 & 5.47 & 12 & 4.23 & 0.60 & $(0.34,1.09)$ & 0.0926 \\
\hline Postoperative bleeding & 126 & 5.03 & 21 & 7.39 & 1.16 & $(0.74,1.81)$ & 0.5245 \\
\hline Epidural anesthesia & 11 & 0.44 & 1 & 0.35 & 0.62 & $(0.09,4.39)$ & 0.6290 \\
\hline Morphine & 1246 & 49.78 & 137 & 48.24 & 0.81 & $(0.65,1.03)$ & 0.0797 \\
\hline
\end{tabular}

$\dagger$ Values are mean and standard deviation.

Hazard ratios are for malignancy as compared with non-malignancy after transplantation. CI denotes confidence interval.

in the cohort interval. Risk factors for each group are summarized in Table 4. Older LTRs were more predisposed to post-transplant malignancies than younger ones (hazard ratio, $1.025 ; 95 \% \mathrm{CI}, 1.016$ to $1.033 ; p<$ $0.0001)$. The risk of post-transplant malignancies was significantly higher in males than in females (hazard ratio, $1.51 ; 95 \% \mathrm{CI}, 1.15$ to $2.00 ; p=0.0033$ ). Patients with a past history of liver cirrhosis (hazard ratio, 1.46; $95 \% \mathrm{CI}, 1.01$ to $2.13 ; p=0.0468$ ) or chronic hepatitis (hazard ratio, 2.00; 95\% CI, 1.06 to $3.77 ; p<0.0329$ ) were predisposed to malignancies. LTRs with hepatitis B, but not hepatitis $\mathrm{C}$ or alcoholic hepatitis, had a significantly elevated risk of cancer $(p=0.0085,0.062$, and 0.6235 , respectively). Furthermore, recipients with biliary atresia (hazard ratio, $0.28 ; 95 \% \mathrm{CI}, 0.16$ to $0.50 ; p<0.0001$ ) or urea cycle metabolism disorders $(p<0.0001)$ appeared to be protected from malignancies. Peptic ulcers (hazard ratio, $1.53 ; 95 \% \mathrm{CI}, 1.21$ to $1.94 ; p=0.0004)$ and diabetes mellitus (hazard ratio, 1.36; 95\% CI, 1.04 to $1.79 ; p=0.0264$ ) were significantly more common in the malignancy group than in the non-malignancy group. In our study, the risk of postoperative malignancies 
was significantly higher in the LTRs with preoperative malignancies (hazard ratio, 3.82; 95\% CI, 2.94 to 4.96; $p$ $<0.0001)$. However, socioeconomic deprivation and other systemic diseases, such as hypertension, lung disease, or renal failure, were not associated with post-transplant malignancies. Postoperative sepsis, postoperative bleeding, epidural anesthesia, and morphine usage were not associated with postoperative malignancies.

\section{Recurrent malignancies considerably increased mortality in the LTRs}

The results revealed increased mortality in the LTRs with postoperative malignancies, and the LTRs with recurrent malignancies had higher mortality than did those with no postoperative malignancies $(\mathrm{RR}=3.15, \mathrm{CI}$ $=2.49$ to 4.00$)$ or with de novo malignancies $(\mathrm{RR}=1.13$, $\mathrm{CI}=0.78$ to 1.64 ), respectively. The result suggested that compared with the de novo or postoperative cancer-free groups, the recurrent group considerably increased LTR mortality (Figure 3).

Overall mortality among the four groups were 5.13\% (143/2787), 9.36\% (261/2787), and 11.12\% (310/2787) at 1,3 , and 5 years, respectively. The mortality rates of the de novo group were $9.52 \%(2 / 21), 12.31 \%(8 / 65)$, and $26.51 \%(22 / 83)$ at 1,3 , and 5 years, respectively. Furthermore, in the recurrent group, the mortality rates were $8.20 \%(5 / 61), 24.85 \%(42 / 169)$, and $30.17 \%$ $(54 / 179)$ at 1,3 , and 5 years, respectively. Moreover, the 10 -year patient mortality rates in the malignancy-free, malignancy-cured, de novo, and recurrent groups were $8.10 \%$ (109/1345), 12.60\% (146/1159), 28.87\% (28/97) and $32.26 \%(60 / 186)$, respectively. These results indicated a strong association of mortality with postoperative malignancies; the LTRs with postoperative malignancies revealed higher mortality, particularly considering those with recurrent malignancies.

\section{DISCUSSION}

In this retrospective study of 2938 LTRs, de novo malignancies occurred in $3.34 \%$ of recipients at a mean relapse time of 5.71 years postoperatively. The recurrence rate among the patients with pre-existing malignancies was $12.92 \%(186 / 1440)$ at a mean elapsed time of 1.71 years. Moreover, the SIR of postoperative de novo cancers was 2.17 -fold (95\% CI, 1.76 to 2.64 ) compared to the general Taiwanese population. Our data are consistent with those of previous studies that reported the tendency to develop malignancies after solid organ transplantation, in which the relative risk ratio was estimated to be between 2.1 and 4.3 [5, 7-9].

Our present study revealed that $65.49 \%(186 / 284)$ of post-transplant malignancies were recurrent. The most common relapse site was the liver, and distal metastasis occurred at the lung and bone or bone marrow. The most common de novo malignancies in the LTRs were HCC (SIR: 3.15, CI: 1.90-4.92), oropharyngeal cancer (SIR: 4.61, CI: 2.77-7.19), and non-Hodgkin's lymphoma (SIR: 8.42, CI: 3.84-15.98), which were all confirmed as infection-related malignancies. The results differed from the prevalence of cancer types in Taiwanese population, in whom the most common malignancies were observed at the colon or rectum, liver, lung, and breast, in that order. Iatrogenic immunosuppression is associated with oncogenesis and immune deficient patients with AIDS also showed significantly higher SIRs for infectionrelated malignancies than the general population. HCC is associated with hepatitis $\mathrm{B}$ and $\mathrm{C}$ virus infection; oropharyngeal cancer is HPV related; and non-Hodgkin lymphoma is Epstein-Barr virus related [10]. In addition, esophageal and gastric cancers were Helicobacter pylori related $[10,17)$, and comprised $8.25 \%$ of de novo malignancies observed in LTRs. Multivariate analysis also revealed that post-transplant malignancies were significantly associated with hepatitis B, but not with hepatitis $\mathrm{C}$ or alcoholic hepatitis. Preoperative hepatitis virus B-infected patients appeared predisposed to oncogenesis after immunosuppression. Furthermore, $H$. pylori infection is a major risk factor for peptic ulcers, infecting $90 \%-100 \%$ and $60 \%-90 \%$ of patients with gastric and duodenal ulcers, respectively [18, 19]. We could not directly evaluate $H$. pylori infection in the LTRs; however, we observed an association between patients with peptic ulcers and malignancies. Vigorously treating peptic ulcers before administering immunosuppressant might reduce post-transplant malignancies, particularly esophageal and gastric cancers; however, further studies are required to support this hypothesis. In conclusion, our results reveal the effect of immunosuppressive treatment on postoperative malignancies in LTRs. A similar risk of cancer in the LTRs and patients with AIDS suggests that immune deficiency is, at least partially, responsible for the increased risk.

In this study of the Chinese ethnicity, skin cancer was relatively rare, estimated to be $1.01 \%$ in the de novo group; however, it is relatively common in de novo malignancies reported in western countries [20]. Skin cancer accounted for $38.67 \%$ of postoperative malignancies in a similar study of the Swedish population [20]. Among post-transplant de novo malignancies, 5.3\% of American recipients and $4.21 \%$ of Australian recipients reported malignancies among solid organs, including the liver, kidneys, heart, and lungs [8, 21]. Furthermore, the postoperative melanoma incidence has been reported as $2 \%-4 \%$ in Swedish and Italian populations [9, 20]; however, no melanoma developed in our cohort.

Age and sex were the major risk factors for posttransplant malignancies, thus warranting detailed screening for malignancies. Patients with comorbidities of preoperative liver cirrhosis, diabetes mellitus, and 
pre-existing cancers were also high-risk populations. Advanced liver fibrosis is a confirmed risk factor for HCC carcinogenesis [22]. Pre-existing malignancies are recurrent in nature, and this factor may be apparent under the effect of tumor surveillance escape as natural killer cells are inhibited by immunosuppressant. Patients with biliary atresia or urea cycle metabolism disorders appear to have a decreased risk of post-transplant cancers. These findings should not be inclusion or exclusion criteria for liver transplant candidates; instead, they must remind clinicians to reduce the immunosuppressant dose and to carefully screen for risk.

A low socioeconomic status is correlated with the incidence and mortality of various malignancies, such as HCC, esophageal, breast, and colorectal cancer [2328]. Our present data revealed no correlation between socioeconomic status and incidence of post-transplant malignancies $(p=0.3312)$. This may have contributed to earlier diagnosis and optimal treatment without the barriers of socioeconomic status because of the patient care provided by the NHI program. This observation was also supported by the relatively lower SIR (2.17fold) of de novo cancer in our cohort compared with that reported by previous studies (2.1 to 4.3 -fold). Iwasaki et al. reported the possible influence of volatile anesthetics on cancer cell biology and metastatic potential in vitro study [29]. However, NHIRD cannot provide any record of anesthetic used in surgery.

The recipients with post-transplant malignancies had a significantly higher mortality; those with recurrent malignancies survived less frequently than those with de novo malignancies. Our data revealed that the mortality of malignancy-cured patients was slightly inferior to that of malignancy-free patients, but lower than that of the de novo and recurrent groups. The 10 -year patient mortality rates were $8.1 \%$ and $12.6 \%$ in the malignancy-free and malignancy-cured groups, supporting the assumption that liver transplantation is a favorable treatment option for localized HCC with no recurrence. Moreover, careful patient selection and an immunosuppression-minimizing strategy are warranted.

The study has some limitations. First, the NHIRD could not provide data on risk factors, such as lifestyle, living or working environment, and family history [30]. Smoking, alcohol consumption, environmental toxins or pollution, and genetic inheritance play crucial roles in oncogenesis. The effects of latency and dosage on these risk factors were also unknown. In addition, the average follow-up interval was relatively short (3.79 \pm 3.26 years) and may cause the underestimation of lateonset carcinogenesis. Second, although the present study revealed risk factors for post-transplant malignancies, the actual causality between them remains unconfirmed. Third, in addition to immunosuppressant-induced malignancy, circulating cancer cells before transplantation, surgical manipulation-induced tumor seeding, and tumorigenesis tendency of recipients were possible risk factors for recurrence of post-transplant HCC unaccounted for in our data.

\section{ACKNOWLEDGMENTS}

Our study analyzed data from the NHIRD, which was provided by the Bureau of National Health Insurance, Department of Health and is governed by the National Health Research Institutes. Interpretation and conclusions reported herein do not represent the views of the Bureau of National Health Insurance, Department of Health or National Health Research Institutes.

\section{CONFLICTS OF INTEREST}

The authors report no conflicts of interest.

\section{REFERENCES}

1. Mazzaferro V, Regalia E, Doci R, Andreola S, Pulvirenti A, Bozzetti F, Montalto F, Ammatuna M, Morabito A, Gennari L. Liver transplantation for the treatment of small hepatocellular carcinomas in patients with cirrhosis. N Engl J Med. 1996; 334:693-699.

2. Duffy JP, Vardanian A, Benjamin E, Watson M, Farmer DG, Ghobrial RM, Lipshutz G, Yersiz H, Lu DS, Lassman C, Tong MJ, Hiatt JR, Busuttil RW. Liver transplantation criteria for hepatocellular carcinoma should be expanded: a 22-year experience with 467 patients at UCLA. Ann Surg. 2007; 246:502-509; discussion 509-511.

3. D'Amico F, Schwartz M, Vitale A, Tabrizian P, Roayaie S, Thung S, Guido M, del Rio Martin J, Schiano T, Cillo U. Predicting recurrence after liver transplantation in patients with hepatocellular carcinoma exceeding the up-to-seven criteria. Liver Transpl. 2009; 15:1278-1287.

4. Watt KD. Keys to long-term care of the liver transplant recipient. Nat Rev Gastroenterol Hepatol. 2015; 12:639648.

5. Aberg F, Gissler M, Karlsen TH, Ericzon BG, Foss A, Rasmussen A, Bennet W, Olausson M, Line PD, Nordin A, Bergquist A, Boberg KM, Castedal M, et al. Differences in long-term survival among liver transplant recipients and the general population: a population-based Nordic study. Hepatology. 2015; 61:668-677.

6. Watt KD, Pedersen RA, Kremers WK, Heimbach JK, Charlton MR. Evolution of causes and risk factors for mortality post-liver transplant: results of the NIDDK longterm follow-up study. Am J Transplant. 2010; 10:14201427.

7. Ajithkumar TV, Parkinson CA, Butler A, Hatcher HM. Management of solid tumours in organ-transplant recipients. Lancet Oncol. 2007; 8:921-932.

8. Engels EA, Pfeiffer RM, Fraumeni JF Jr, Kasiske BL, 
Israni AK, Snyder JJ, Wolfe RA, Goodrich NP, Bayakly AR, Clarke CA, Copeland G, Finch JL, Fleissner ML, et al. Spectrum of cancer risk among US solid organ transplant recipients. JAMA. 2011; 306:1891-1901.

9. Ettorre GM, Piselli P, Galatioto L, Rendina M, Nudo F, Sforza D, Miglioresi L, Fantola G, Cimaglia C, Vennarecci G, Vizzini GB, Di Leo A, Rossi M, et al. De novo malignancies following liver transplantation: results from a multicentric study in central and southern Italy, 1990-2008. Transplant Proc. 2013; 45:2729-2732.

10. Grulich AE, van Leeuwen MT, Falster MO, Vajdic CM. Incidence of cancers in people with HIV/AIDS compared with immunosuppressed transplant recipients: a metaanalysis. Lancet. 2007; 370:59-67.

11. Chak E, Saab S. Risk factors and incidence of de novo malignancy in liver transplant recipients: a systematic review. Liver Int. 2010; 30:1247-1258.

12. Chandok N, Watt KD. Burden of de novo malignancy in the liver transplant recipient. Liver Transpl. 2012; 18:12771289.

13. Moreno P, Jaurrieta E, Figueras J, Benasco C, Rafecas A, Fabregat J, Torras J, Casanovas T, Casais L. Orthotopic liver transplantation: treatment of choice in cirrhotic patients with hepatocellular carcinoma?. Transplant Proc. 1995; 27:2296-2298.

14. Van Thiel DH, Carr B, Iwatsuki S, Selby RR, Fung JJ, Starzl TE. The 11-year Pittsburgh experience with liver transplantation for hepatocellular carcinoma: 1981-1991. J Surg Oncol Suppl 1993;3:78-82.

15. Regalia E, Coppa J, Pulvirenti A, Romito R, Schiavo M, Burgoa L, Mazzaferro V. Liver transplantation for small hepatocellular carcinoma in cirrhosis: analysis of our experience. Transplant Proc. 2001; 33:1442-1444.

16. Li WH, Chen YJ, Tseng WC, Lin MW, Chen TJ, Chu SY, Hwang CY, Chen CC, Lee DD, Chang YT, Wang WJ, Liu HN. Malignancies after renal transplantation in Taiwan: a nationwide population-based study. Nephrol Dial Transplant. 2012; 27:833-839.

17. Venerito M, Vasapolli R, Rokkas T, Malfertheiner P. Helicobacter pylori and Gastrointestinal Malignancies. Helicobacter. 2015; 20 Suppl 1:36-39.

18. Miftahussurur M, Yamaoka Y. Helicobacter pylori virulence genes and host genetic polymorphisms as risk factors for peptic ulcer disease. Expert Rev Gastroenterol Hepatol. 2015; 1-13.

19. Tytgat GN. Treatment of peptic ulcer. Digestion. 1998; 59:446-452.

20. Krynitz B, Edgren G, Lindelof B, Baecklund E, Brattstrom C, Wilczek H, Smedby KE. Risk of skin cancer and other malignancies in kidney, liver, heart and lung transplant recipients 1970 to 2008--a Swedish population-based study. Int J Cancer. 2013; 132:1429-1438.
21. Na R, Grulich AE, Meagher NS, McCaughan GW, Keogh AM, Vajdic CM. Comparison of de novo cancer incidence in Australian liver, heart and lung transplant recipients. Am J Transplant. 2013; 13:174-183.

22. Iio E, Ocho M, Togayachi A, Nojima M, Kuno A, Ikehara Y, Hasegawa I, Yatsuhashi H, Yamasaki K, Shimada N, Ide T, Shinkai N, Nojiri S, et al. A novel glycobiomarker, Wisteria floribunda agglutinin macrophage colonystimulating factor receptor, for predicting carcinogenesis of liver cirrhosis. Int J Cancer. 2016; 138(6):1462-1471.

23. Dik VK, Aarts MJ, Van Grevenstein WM, Koopman M, Van Oijen MG, Lemmens VE, Siersema PD. Association between socioeconomic status, surgical treatment and mortality in patients with colorectal cancer. Br J Surg. 2014; 101:1173-1182.

24. Jansen L, Eberle A, Emrich K, Gondos A, Holleczek B, Kajuter H, Maier W, Nennecke A, Pritzkuleit R, Brenner $H$. Socioeconomic deprivation and cancer survival in Germany: an ecological analysis in 200 districts in Germany. Int J Cancer. 2014; 134:2951-2960.

25. Parise CA, Caggiano V. Disparities in race/ethnicity and socioeconomic status: risk of mortality of breast cancer patients in the California Cancer Registry, 2000-2010. BMC Cancer. 2013; 13:449.

26. Peng W, Chen Y, Jiang Q, Zheng Y. Spatial analysis of hepatocellular carcinoma and socioeconomic status in China from a population-based cancer registry. Cancer Epidemiol. 2010; 34:29-33.

27. Sharpe KH, McMahon AD, McClements $\mathrm{P}$, Watling $\mathrm{C}$, Brewster DH, Conway DI. Socioeconomic inequalities in incidence of lung and upper aero-digestive tract cancer by age, tumour subtype and sex: a population-based study in Scotland (2000-2007). Cancer Epidemiol. 2012; 36:e164170 .

28. Wang N, Cao F, Liu F, Jia Y, Wang J, Bao C, Wang X, Song Q, Tan B, Cheng Y. The effect of socioeconomic status on health-care delay and treatment of esophageal cancer. J Transl Med. 2015; 13:241.

29. Iwasaki M, Zhao H, Jaffer T, Unwith S, Benzonana L, Lian Q, Sakamoto A, Ma D. Volatile anaesthetics enhance the metastasis related cellular signalling including CXCR2 of ovarian cancer cells. Oncotarget. 2016; 7:26042-26056. doi: 10.18632/oncotarget.8304.

30. Wogan GN, Hecht SS, Felton JS, Conney AH, Loeb LA. Environmental and chemical carcinogenesis. Semin Cancer Biol. 2004; 14:473-474. 